DOI: $10.20472 / T E .2018 .6 .2 .005$

\title{
HEALTH AND WELLBEING STATUS AMONG STUDENTS OF THE FACULTY OF PHYSICAL EDUCATION AND SPORTS: GENDER DIFFERENCES AND MARITAL STATUS
}

\author{
SHQIPE BAJCINCA - BRESTOVCI, LIRIDONA JEMINI - GASHI*, MELIHA \\ BRESTOVCI, LIRIE LOKAJ
}

\begin{abstract}
:
Worldwide studies show the importance of physical activity for health and wellbeing. The purpose of the current study was to analyze health and well-being of students at the Faculty of Physical Education and Sports who have regular physical activity. The study also aimed to analyze health and well-being from a gender perspective and marital status. A series of validated measures assessing health and wellbeing and additional questions for the demographic part, were administrated to 428 students of Sports (Female $42.5 \%$, Male $=57.5 \%, 33.5 \%$ married, 61\% unmarried). Research findings show high levels of physical, mental, social, emotional and spiritual health and well-being among sports students. Most of the students do not consume unhealthy and psychoactive substances. In addition to descriptive data, the findings of the study show significant differences in health and wellbeing, as per gender, as well as for marital status. Results have come to be consistent with data derived from other studies and are discussed within the context of general and specific dimensions of health and wellbeing, physical education and activity among Kosovar students.
\end{abstract}

\section{Keywords:}

students, physical activity, health, wellbeing, gender differences, marital status

JEL Classification: $100,110,112$

\section{Authors:}

SHQIPE BAJCINCA - BRESTOVCI, University of Prishtina , Kosovo, Email: shqipe.bajcinca@uni-pr.edu LIRIDONA JEMINI - GASHI*, University of Prishtina, Kosovo, Email: liridona.jemini@uni-pr.edu MELIHA BRESTOVCI, University of Prishtina, Kosovo, Email: meliha.brestovci@uni-pr.edu LIRIE LOKAJ, Ambulance of Clinical Psychology “UNI”, Kosovo, Email: lokaj.lirie@gmail.com

\section{Citation:}

SHQIPE BAJCINCA - BRESTOVCI, LIRIDONA JEMINI - GASHI*, MELIHA BRESTOVCI, LIRIE LOKAJ (2018). Health and wellbeing status among students of the Faculty of Physical Education and Sports: gender differences and marital status. International Journal of Teaching and Education, Vol. VI(2), pp. 75-86., 10.20472/TE.2018.6.2.005

*Corresponding author 


\section{Introduction}

Health and wellbeing are very important life factors, and researchers around the world are getting more attention to them. Regarding health and wellbeing, in literature there are highlighted different theoretical perspectives. Some researchers conceptualize health and wellbeing as an emotional process (Dinner, Emmons, Larsen and Griffen, 1985). Suominen, Helenius, Blomberg, Uutela and Koskenvuo (2000) have stressed that health and wellbeing are related to physical processes. Moreover, according to them, physical health is a good predictor of life quality. Other researchers (Martin and Rubin, 1995; Stephen, Dulberg and Joubert, 1999) have described wellbeing as a cognitive process. The World Health Organization defined health as a physical, mental and social state, and wellbeing as a balance of these dimensions (WHO, 2002; 2006).

Another model bases health on five dimensions. According to Masters (2004), health consists of five dimensions: physical health, social, emotional, mental and spiritual, while wellbeing means a balance of the dimensions concerned. The physical dimension of health refers to the body aspect, the traditional definitions of health and the absence of diseases and injuries. Mental health consists in the cognitive aspect of health, while emotional health has to do with the ability to recognize and express feelings adequately. Spiritual health refers to the general feeling of living in life, whilst the social dimension of health consists in the ability to make and maintain meaningful relationships with others (Masters, 2004).

Health and wellbeing are factors of interest for many studies that aim to analyze them from different perspectives. Associated to health and wellbeing, there are many factors, including the part of physical education and sport. Numerous studies around the world show the importance of physical activity for general and specific dimensions of health and wellbeing.

It has been shown that education and health are "partners" working together. Therefore, one promotes the other and together they promote the wellbeing of students (Strong, Malina, Blimkie, 2005). According to Fedewa and Ahn (2011), physical activity leads to many psychological and health benefits. Physical education in schools offers to students a platform from which they can gain physical skills, improve fitness, develop personal and interpersonal skills and improve children's achievement and cognitive outcomes (Fedewa, Ahn, 2011). It also enables students to develop the concepts and skills necessary for participation in a wide range of physical activities, including sports, dance and outdoor learning, and enhances their physical wellbeing in preparation for leading a fulfilling, active and healthy lifestyle.

According to Brooks (2013), children's wellbeing is influenced by a range of factors and includes their subjective feelings as well as social, physical and psychological aspects of their lives. The health and wellbeing of children and young people contributes to their ability to benefit from good quality teaching and to achieve their full academic potential. In other 
words, academic success has a strong positive impact on children's subjective sense of how good they feel their lives are (life satisfaction) and is linked to higher levels of wellbeing in adulthood (Brooks, 2013).

The role of physical activity in the wellbeing of individuals, was also examined in the study of Rendi, Szabo, Szabo, Velenczeei and Kovacs (2008), which included participants with regular physical activity. Their aim was to analyze the psychological wellbeing of adults after exercise and gymnastics training. The findings of the study have shown significant improvements after 20 minutes of exercise, regardless of the type and weight of the exercises they have made.

In addition to association of physical activity with health and wellbeing, the studies have been aimed at understanding whether gender differences and marital status for health and well-being exist.

As to gender issues, Roothman, Doret, Kirsten and Marie P. (2003) aimed to examine whether men and women differ with regard to aspects of health and psychological wellbeing. The participants completed 13 scales that measure psychological wellbeing in affective, physical, cognitive, spiritual, self, and social aspects. According to the research findings, men scored higher on physical self-concept, automatic thoughts (positive), constructive thinking, and cognitive flexibility, whereas women scored higher on the expression of affect, somatic symptoms, and religious wellbeing. The researchers concluded that no significant gender differences were found regarding coherence, life satisfaction, affect balance, and emotional intelligence, as results are in line with gender stereotypes and traditional socialization practices, and possibly reflect the impact of longstanding social inequality between men and women. Gender differences regarding physical activity and different aspects of health and well-being including physical, mental, social, emotional and spiritual dimensions, are also emphasized by other studies (Carmel \& Bernstein, 2003; Hammermeister, Flint, El-Alayli, Ridnour, \& Peterson, 2005; Savoye, Moreau, Brault, Levêque \& Godin, 2015).

Among recent studies, those that gained attention were on women's wellbeing across different disciplines. These researches take into account the relationship between psychological wellbeing and major life transitions, including marriage. However, there are not enough studies on the nature of the relationship between marital status and psychological wellbeing, as most of the studies on marital transition and psychological wellbeing were conducted in a developed country setting (e.g. Pearlin \& Johnson, 1977; Gerstel, Riessman \& Rosenfield, 1985; Diener, 1984; Horwitz, White \& Howell-White, 1998). Pearlin and Johnson (1977) reported that those who are married are less susceptible to depression, even after controlling for important characteristics such as sex, age, and race. Their study also reveals that separated individuals are the most burdened by depression, while widowed and divorced individuals are troubled with it only to a moderate degree. Gerstel, Reissman and Rosenfield (1985) also found evidence 
associating marital dissolution with psychological distress and showed gender differences in this association. For women, psychological distress following marital dissolution tends to be associated with material circumstances (i.e. those concerning income and other parental obligations), whereas for men the consequence is strongly felt in the loosening of social networks. Horwitz, White, and Howell-White (1998), however, do not show similar gender differences for younger cohorts. They report that young married men and women derive equal benefits from marriage and experience increased levels of wellbeing in terms of, e.g., reduced psychosomatic symptoms and less alcohol intake.

The perception of health and wellbeing by students, as affected by gender and marital status, is also studied by Pandey (2009/10). Through cross-sectional studies, interaction between marital status and health-and-wellbeing, shows that married people report higher scores on their health and wellbeing. Such findings have been shown also in the study of Mookherjee (1997). Marriage was seen to have raised a higher level of perception of health and wellbeing for men and women, though married women have reported more satisfaction than men. This has been emphasized and explained by other studies. According to Soulsby and Bennett (2015), married people report consistently better levels of psychological health than unmarried through perception of social support. Based on the findings, married people perceive a higher social support and so, they report for a better psychological and general health and wellbeing. On the other hand, the unmarried, divorced and the widows, have reported a lower psychological health and wellbeing.

Worldwide, studies make clear enough the importance of physical activity for good health and wellbeing. On the other hand, they also emphasize gender differences and marital status in health and wellbeing. Scientific data about these variables are very limited in Kosovo. A study done by Tishukaj, Shalaj, Gjaka, Ademi Ahmetxhekaj, Bachl, Tschan and Wessner (2017), aimed to examine anthropometric and physical fitness parameters in 14 to 15 year old kosovar adolescents living in rural and urban areas. Research findings showed association of physical performance with overweight and obesity. In other words, worse physical performance was associated with a higher risk for overweight and obesity among kosovar adolescents (Tishukaj, Shalaj, Gjaka, Ademi Ahmetxhekaj, Bachl, Tschan and Wessner, 2017). The study underlines the importance of physical performance, though, data on health and wellbeing of adults with regular physical activity, from a gender perspective and civil status, are missing in Kosovo. The current study is thought to be an initial basis for the health and wellbeing of people with regular physical activity. To the authors' knowledge, this study, is the first to provide information about health and wellbeing among Kosovar adult with regular physical activity.

The overall goal of this study is to understand the level of health and wellbeing of students at the Faculty of Physical Education and Sports, University of Prishtina, "Hasan Prishtina", who have regular physical activity on a daily basis. The study also attempts to provide data on the consumption of prescribed psychoactive substances. Additionally, the study will analyze the status of students on their health and wellbeing in terms of gender and marital 
status. Furthermore, the specific objective of the study is focused on trying to understand if there are differences in health and wellbeing between females and males, married, unmarried, divorced and widows students. Research findings will provide firm ground for the development of strategies and pre-university and university education practices with the aim of motivating people to include in physical activities. The findings from this study will also be a good basis for further studies.

\section{Methods}

\section{Sample}

The study was conducted with 428 students from the Faculty of Physical Education and Sport, in their first, second, third, and fourth year of studies, with an average age of 20.6. Regarding gender, 182 were women (42.5\%) and 246 were men (57.5\%). Sixty-one percent of the sample were unmarried, 33.5\% married, 3.2 divorced, and 2.3 widowers. The sample was intentional on the basis of the intention to bring people who are regular in physical activity, who were then selected through stratified random sampling.

\section{Instruments}

Part of the demographic data. The questionnaire has contained questions about the demographic data of the participants, such as gender, age, residence, educational level and civil status.

The questionnaire on health and wellbeing. It was designed specifically for this study and contains 23 items that measure aspects of health and wellbeing, involvement in physical activity, and consumption of tobacco and beverages containing alcohol. It was designed to support a five-dimensional model (G. Masters 2004), including within itself questions related to the physical, social, emotional, mental, and spiritual dimensions. For the physical dimension, questions were related to nutrition, exercise, and healthy habits. The emotional dimension contained items associated with feelings and the awareness and acceptance of feelings; the mental part consisted of items related to coping with daily problems and demands. Items concerning relationships and interactions with others were drawn to the social dimension, and items regarding beliefs and values to the spiritual dimension.

Pilot instrument was subjected to test its credibility. We tested 50 respondents; the survey resulted in a coefficient of Cronbach's Alophes of $\alpha .824$. 


\section{Research design}

Health and wellbeing of students were criterion variables in this study, and will be analyzed in terms of their general perspective. The variables in question, except in terms of the level of presentation according to students reports, will be analyzed for gender and marital status. The study initially consists of descriptive and explorative design and provides basic data on the health and well-being of Sports students. In line with its specific objectives, the study then moves into inferential statistics with the aim of analyzing data from a civil status and gender perspective. In terms of time, it is a cross-sectional study design. Since the sample includes only students, it is a single cross-sectional design.

\section{Procedure}

With approval of the request for research, the management of the academic unit has agreed to administer the questionnaires with leaders of study programs within the Faculty of Physical Education and Sports. At least two weeks before administration, selected students for the study were informed that on a certain date they would be invited to fill in questionnaires regarding perceptions of their health and wellbeing. Awareness has been adapted for research, including information about a) the purpose of the research, anticipated duration and procedures; b) the right to refuse participation and the opportunity to withdraw after the research began; c) any benefit from the research in the future.

\section{Analysis}

Percentages were used to understand the levels of health and wellbeing in all dimensions, physical, social, emotional, mental and spiritual health and wellbeing. Shapiro Wilk's test was used to check if the data were normally distributed. Data found to be non-normally distributed and therefore non - parametric tests were used. Mann Whitney $U$ was used to investigate the differences for health and well-being among males and females students. While, for understanding the health and wellbeing and the differences between married, unmarried, divorced and widows, Kruskal wallis was used. All analyses were conducted using the Social Package for Social Sciences (SPSS) software, v.20.

\section{Results}

Through frequencies, the perceptions of students are analyzed on the level of their health and wellbeing. In general aspects of health and wellbeing, findings show that $72.96 \%$ of students reported an excellent level, $21.73 \%$ reported health and wellbeing at moderate levels, and $5.31 \%$ of students reported poor health and wellbeing. Regarding the analysis of health and wellbeing in specific dimensions, $75.93 \%$ of students reported an excellent and high level, $19.96 \%$ reported a moderate level, and $31.4 \%$ of students reported poor 
health and physical wellbeing. Regarding health and wellbeing in social terms, $73.32 \%$ of students reported excellent and high levels, 20.92\% a moderate level, and $5.76 \%$ of students reported poor health and social wellbeing. Sixty-nine percent of students reported emotional health and wellbeing at a high and excellent level, 24.64\% reported moderate levels, and $6.36 \%$ reported a weak emotional level. Regarding health and wellbeing in the mental dimension, $68.73 \%$ of students reported a high and excellent level, $20.12 \%$ of students reported a moderate level, while $11.15 \%$ reported a weak level of mental health and wellbeing. Regarding the spiritual dimensions, $66.87 \%$ of students reported high and excellent levels of their spiritual health and wellbeing, $24.66 \%$ reported moderate levels of this dimension, and $8.47 \%$ of the students reported a poor level of health in terms of spiritual wellbeing. In all dimensions, the majority of participants reported high levels of health and well-being.

Findings emerged from a frequency analysis to show the levels of tobacco consumption among students in the Faculty of Physical Education and Sports. Regarding this issue, $7.01 \%$ of the students reported that they smoke on a daily basis; $7.01 \%$ reported smoking occasionally, while $85.75 \%$ reported that they have never smoked. Regarding the consumption of beverages containing alcohol, the highest percentage of students also reported that they have never tried; respectively, $60.28 \%$ of them reported that they have not consumed liquor, $33.19 \%$ of them reported having consumed an occasionally drink containing alcohol, and 6:54\% of students reported consuming alcohol on a daily basis.

These percentages show that most of the students of the Faculty of Physical Education and Sports who have regular physical activity do not consume unhealthy and psychoactive substances.

Besides the abovementioned percentages that correspond to a general objective of the study, there are also statistics comparing means to respond to other specific objectives of the study. Through the normality test of Shapiro Wilk, it is seen that the data distribution is non- normal (statistic .946, df .321, sig.000). Therefore, to understand whether significant differences exist in the health and wellbeing of females and males, the Mann-Whitney $U$ test is used.

Table 1. The health and wellbeing of women and men

\begin{tabular}{lcccr}
\hline Gender & $N$ & Mean & Mann Whitney U & ISig \\
\hline Women & 182 & 188.87 & 11820.000 & .004 \\
Men & 246 & 143.63 & &
\end{tabular}

Note: Means for health and wellbeing according to gender, values and Mann Whitney $U$ and Significance. 
Based on the findings presented in Table Number 1, Mean for health and wellbeing of females is $M 188.87$, while for males is $M$ 143.63. Mann Whitney $U$ value has come to be 11820.00 and sig. .004. As it is assumed, significant differences have been found between females and males for health and wellbeing. Regarding the means values, females reported better health and wellbeing.

To analyze differences in health and wellbeing among students with the civil status of single, married, divorced, and widowed, Kruskal Wallis is used. The results obtained from this analysis are presented in Table Number 2.

Table 2.

Health and wellbeing of those married, single, divorced, and widowed.

\begin{tabular}{|c|c|c|c|c|}
\hline Civil Status & $N$ & Mean & Kruskal Wallis & ISig \\
\hline Not married & 220 & 99.96 & & \\
\hline Married & 190 & 110.78 & & \\
\hline Divorced & 13 & 87.17 & & \\
\hline \multirow[t]{2}{*}{ Widowed } & 5 & 66.97 & & \\
\hline & & & 13.704 & .003 \\
\hline
\end{tabular}

On the basis of results derived and presented in Table 2, it may be noted that health and wellbeing Mean for participants with the civil status of unmarried is $M 99.96$; for married participants $M$ 11.78; for divorced, $M$ 87.17, and for widowed participants, $M$ 66.97. The Kruskal Wallis score for statistics has come to be 13,704 worth of significances of sig.003. Significant differences in health and wellbeing have emerged among the participants of different civil status. The highest average of good health and well-being, is shown by participants who are married, followed by the unmarried participant. Lowest means for health and wellbeing, were reported by the participants who were divorced and widows.

\section{Discussion}

The overall aim of this study was the examination and analysis of the health and wellbeing of students in the Faculty of Physical Education and Sports. The outcomes through descriptive statistics and frequency respectively, have provided an overview for levels of 
health and wellbeing according to perception and reporting by the participants. The outcomes on levels of health and wellbeing in the general framework, show that most of the students of the Faculty of Physical Education and Sports have excellent health $(72.96 \%), 21.73 \%$ are shown to have moderated levels of health and wellbeing, while $31.5 \%$ have reported poor health and wellbeing. The health and wellbeing of students participating is found to be excellent for the majority of students and for the analysis of specific dimensions. Most of the students, or $75.93 \%$, have reported excellent physical health, $19.76 \%$ reported moderate health, and $4: 31 \%$ poor physical health. In the social dimension, $73.32 \%$ of the students participating have talked about excellent social health, while $20.92 \%$ reported a moderate level, and $5.76 \%$ poor wellbeing, poor health and poor social health as well. Regarding the dimension of health and emotional wellbeing, $69 \%$ of participating students have reported excellent health, $24.64 \%$ of them reported a moderate level, and $6.36 \%$ a weak level of emotional wellbeing. For health and wellbeing in the mental dimension, $68.73 \%$ of students have reported a high and excellent level, $20,12 \%$ of students reported a moderate level, while $11.15 \%$ of them reported a weak level of mental health and wellbeing. On the spiritual dimension, $66.87 \%$ of students have reported high and excellent levels of health and spiritual wellbeing, $24.66 \%$ reported moderate levels, and $8: 47 \%$ of the students reported a poor level of health and wellbeing in this dimension. These findings confirm the importance of regular physical activity for high levels of health and wellbeing.

In general, the findings of this study in Kosovo are consistent with the findings of many other studies worldwide. The excellent levels of health and wellbeing among students in the Faculty of Physical Education and Sport are in line with the findings of other studies. The importance of physical activity on general health and wellbeing is also found in study of Marchi and Uzoniche, (2010; in Olubayo-Fatiregun, Ayodele, \& Olorunisola 2014), according to which, involvement in activities such as regular sports improves the health and wellbeing of persons at any age. According to them (Marchi \& Uzoniche 2010 in Olubayo-Fatiregun, Ayodele, \& Olorunisola, 2014), engagement in physical activities prevents many diseases such as cardio-vascular and coronary artery disease, diabetes, obesity, and some forms of cancer. Emphasizing the association of physical activity and health, current research findings are consistent with the findings of other studies (Tishukaj, Shalaj, Gjaka, Ahmetxhekaj, Bachl, Tschan, 2017; Rendi, Szabo, Szabo, Velenczeei and Kovacs, 2008).

Regarding the specific objectives of the study, the results provide data also in regard to the specific research questions. Regarding the gender perspective, the results obtained through the Mann-Whitney $U$ (11820.000, sig. Of .004) show significant differences for health and wellbeing between females and males. On the basis of this, it can be concluded that significant differences exist between females and males for health and wellbeing, where females have reported the higher mean that for better health and wellbeing. 
Significant differences from the perspective of gender when it comes to health and wellbeing are found by other studies, some at the global level, while in some others, differences between men and women were found among the various dimensions of health and wellbeing (Graham and Chattopadhyay, 2012; Roothman, Kirsten and Marie, 2003; Horwitz, White and Howell-White 1996; Carmel \& Bernstein, 2003; Hammermeister, Flint, El-Alayli, Ridnour, \& Peterson, 2005; Savoye, Moreau, Brault, Levêque \& Godin, 2015).

Significant differences for health and wellbeing are found even between married students and unmarried, divorced, and widowed. Based on the results obtained by Kruskal Wallis (M 110.78 to married, unmarried M 99.96, 87.17 Kruskal Wallis with sig. of .003), married participant students have shown the highest mean of good health and wellbeing. These findings are consistent with the findings of other studies which emphasize the importance of marriage in the health and wellbeing of women and men (Pearlin \& Johnson, 1977; Gerstel, Riessman \&Rosenfield, 1985; Doherty, Su \& Needle, 1989; Horwitz, White \& Howell-White, 1996; e Pandey 2009/10; Mookherjee, 1997). This can be explained by the benefits of marriage (Stanton, 2012) and people who are married enjoy better health in the physical aspect and also in the mental one. According to Stanton (2012), married individuals are more likely to be happy, avoid acute diseases, and care more about themselves; they also avoid risky behaviors. Similar findings were reported in the study of Kulikova and Llull (2014), according to whom married people enjoy significantly better health than the unmarried ones and married people report social support, which then affects psychological health and well-being (Soulsby and Bennett, 2015). Such findings are also explainable in the Kosovo context, where marriage is perceived among the most important life matters.

\section{Conclusion}

Regarding overall purpose and specific objectives, this study raises important issues concerning health and wellbeing, especially in a population for which we do not have scientific data. Students at the Faculty of Physical Education and Sports have shown high levels of health and excellent wellbeing. Students involved in regular physical activities, to a great extent report not consuming unhealthy substances. Although differences in the means for health and wellbeing of females and males are not large, they are significant. Women have reported the highest level of good health and wellbeing. Also, high and excellent levels of health and wellbeing showed more participants who were married than unmarried, divorced, or widowed. Differences in health and wellbeing for the civil status, have shown to be significant. Results of the study are in line with other studies, and may have theoretical but also practical implications.

Finally, the findings of this study provide the first evidence that the health and well-being of sports students doing regular physical activities are at a high level, both in terms of general 
and specific dimensions. Physical activity represent a vital factor for health and wellbeing. Based on the findings of this study, further studies may focus on other variables that may correlate with the health and wellbeing of the population in Kosovo. Future studies would be better to include other students from different academic units in order to analyze and compare health and wellbeing of students in different faculties and, based on the findings, more specific recommendations would come up. These findings provide an initial and good basis for the development of strategies and programs at education system for adequate integration of physical education and sports. On the basis of this study and others that may take place later, awareness programs can be developed on the importance of physical activity for overall health and wellbeing of the population of Kosovo, all ages included.

\section{References}

Brett Roothman, Doret K. Kirsten and Marie P.,Gender. differences in aspects of psychological wellbeing, Wissing School of Psychological Behavioural Sciences, Potchefstroom University for CHE, South Africa.

Brooks F ( 2013). Chapter 7: Life stage: School Years, in Chief Medical Officer's annual report 2012: Our Children Deserve Better: Prevention Pays, ed. Professor Dame Sally C Davies. London: DH

Carmel, S. \& Bernstein, J. (2003). Gender differences in physical health and psychosocial well being among four age-groups of elderly people in Israel. International Journal of Aging \& Human Development, 56(2), 113-

131

Carol Graham and Soumya Chattopadhyay (2012). Gender and Wellbeing Around the World: Some Insights from the Economics of Happiness. Working Papers from Human Capital and Economic Opportunity Working Group.

Diener, Ed. 1984. "Subjective Wellbeing." Psychological Bulletin 95: 542-575. https://doi.org/10.1037/00332909.95.3.542

Diener, E., Emmons, R. A., Larsen, R. J., \& Griffin, S. (1985). The Satisfaction With Life Scale. Journal of Personality Assessment, 49, 71-75

Fedewa AL, Ahn S. (2011). The effects of physical activity and physical fitness on children's achievement and cognitive outcomes: a meta-analysis.Res Q Exerc Sport. 2011;82(3):521-535.

Gerstel, Naomi, Catherine Kohler, and Sarah Rosenfield. 1985. "Explaining the Symptomatology of Separated and Divorced Women and Men: The Role of Material Conditions and Social Networks." Social Forces 64: 84-101

Hammermeister, J., Flint, M., El-Alayli, A., Ridnour, H \& Peterson, M. (2005). Gender differences in spiritual wellbeing: Are females more males spiritually - well than males? American Journal of Health Studies. 2005, Vol. 20 Issue 1/2, p80-84. 5p.

Horwitz, Allan V., Julie McLaughlin, and Helene Raskin White. 1997. "How the Negative and Positive Aspects of Partner Relationships Affect the Mental Health of Young Married People." Journal of Health and Social Behavior 39: 124-136.

Masters G, 2004 Conceptualising and researching student wellbeing http://www.acer.edu.au/documents/RC2004 Proceedings 001.pdf 
Martin, M. M., \& Rubin, R. B. (1995). A new measure of cognitive flexibility. Psychological Reports, 76, 623626

Mookherjee, Dilip. "Informational Rents and Property Rights in Land." In Property Relations, Incentives and Wellbeing, edited by John E. Roemer. New York: Macmillan, 1997

Olubayo-Fatiregun, M. A., Ayodele R.B, \&.Olorunisola, H.K (2014). Health, Fitness and Physical Activity: A Key to Enhancing Wellness for All Ages in Building a Vibrant Nation. Asian Journal of Humanities and Social Sciences (AJHSS) Volume 2-Issue 1, February, 2014 ISSN: 2320-9720

Olubayo-Fatiregun, Ayodele, \& Olorunisola (2014). Health, Fitness and Physical Activity: A Key to Enhancing Wellness for All Ages in Building a Vibrant Nation. Asian Journal of Humanities and Social Sciences (AJHSS) Volume 2-Issue 1, February, 2014 ISSN: 2320-9720

Pandey, M.K. (2009/10). Association between Marital Status and Health: Examining the Role of Age and Gender1 .ASARC Working Paper

Pearlin, Leonard I. and Joyce S. Johnson. 1977. "Marital Status, Life Strains and Depression." American Sociological Review 42: 704-715.

Rendi, M., Szabo, A., Szabó, T., Velenczei, A., \& Kovács, Á. (2008). Acute psychological benefits of aerobic exercise: A field study into the effects of exercise characteristics. Psychology, Health \& Medicine, 13(2), 180-184. doi:10.1080/13548500701426729

Roothman, B., Kirsten, D. \& Wissing, P. (2003). Gender differences in aspects of psychological wellbeing. Periodical | South African Journal of Psychology, Vol 33, Issue 4, p. p.212-218.

Savoye, I., Moreau, N., Brault, M.Ch., Levêque , A \& Godin, I. (2015). Well-being, gender, and psychological health in school-aged children. v.73; PMC4685636. Arch Public Health.

Soulsby, L. K., \& Bennett, K. M. (2015). Marriage and Psychological Wellbeing: The Role of Social Support. Psychology, 6, 1349-1359. http://dx.doi.org/10.4236/psych.2015.611132

Stephens T, Dulberg C, Joubert N (1999). Mental health of the Canadian population: a comprehensive analysis. Chronic Diseases in Canada, 20(3): 118-126.

Strong WB, Malina RM, Blimkie CJ (2005). Evidence based physical activity for school-age youth. J Pediatr;146(6):732-737.

Suominen S, Helenius $H$, Blomberg $H$, Uutela $A$, Koskenvuo $M$. Sense of coherence as a predictor of subjective state of health. Results of a 4-year follow-up of adults. J Psychosom Res. 2001; 50: 7786. Google Scholar Medline

Tishukaj, F., Shalaj, I., Gjaka, M., Ahmetxhekaj, A., Bachl, N., Tschan, H., \& B. (2017). Physical fitness and anthropometric characteristics among adolescents living in urban or rural areas of Kosovo. BMC Public Health. https://doi.org/10.1186/s12889-017-4727-4

World Health Organization. WHO definition of Health, Preamble to the Constitution of the World Health Organization as adopted by the International Health Conference, New York, 19-22 June 1946; signed on 22 July 1946 by the representatives of 61 States (Official Records of the World Health Organization, no. 2, p. 100) and entered into force on 7 April 1948. In Grad, Frank P. (2002). "The Preamble of the Constitution of the World Health Organization". Bulletin of the World Health Organization. 80 (12): 982.

World Health Organization. (2006). Constitution of the World Health Organization - Basic Documents, Fortyfifth edition, Supplement, October 2006. 